\title{
THE APPLICATION AND EFFECTS OF THE EUROPEAN COMMISSION WHITE PAPER ON EU GOVERNANCE IN THE EU GOVERNANCE FRAMEWORK.
}

\author{
Lisa Laura Maria Verhasselt, Postgraduate Student \\ London School of Economics and Political Science \\ Luxembourg/ Luxembourg \\ lisa-laura.verhasselt@outlook.com
}

\begin{abstract}
This article scrutinises the effects of the Commission's agenda for European governance reforms set out in the White Paper on European Governance (WPG). The White Paper was adopted in 2001 with the aim to establish more democratic forms of governance at various levels, ranging from global to local, and as a response to the often-proclaimed democratic deficit of the European Union (EU), and the citizens increasingly distrust and indifference towards the EU. Another aim is to focus on how possibilities for civil society inclusion have evolved since 2001.

The WPG is scrutinised in a retrospective angle at the hand of the framework for ex-post evaluation. In making an assessment of the White Paper it is useful to consider benchmarks; effectiveness and relevance are the key criteria that should be adopted in order to evaluate a given piece of legislation. The symmetry principle is employed to increase the understanding of the EU's fight for democratic legitimacy. The findings indicate that more than a decade after its creation, the WPG must be appraised in light of its achievement: it has provided the necessary impetus to reform the European governance agenda.
\end{abstract}




\section{Keywords}

Democratic Deficit, the European Union, Ex Post Evaluation Framework, Governance, Symmetry Principle White Paper

\section{INTRODUCTION}

Historically, one can identify two types of democracy at EU level, namely representative and participatory democracy. Until the 1990s the EU mainly focused on its representative democracy by means of enhancing the European Parliament's (EP) competencies. However, by the mid-1990s one could observe a crisis of the EU's legitimacy. Citizens felt alienated and the Union realised the need to focus on its democratic credentials since there was no doubt there was a profound crisis of trust. When the EC led by Romano Prodi took office in 2000, a new era for European governance began. The promotion of new and better forms of governance in order to achieve a more efficient, democratic and open European Union became a strategic objective for the Commission's five years ahead. As a first step in this process, the WPG was adopted on 25 July 2001. Initially, when the EC adopted the WPG in 2001, it was considered the turning point for the EU, i.e. the participatory turn of EU decision-making. It nourished hopes that the EU could democratically reform European governance through bringing the Union closer to its citizens. Sceptics, nevertheless, called the practical utility of the document into question and after more than a decade, questions remain. Has the EU witnessed a participatory turn? Has the White Paper transformed European governance? To which extent has the White Paper transformed European governance? This research seeks to explore the alleged weak WPG to give an overview of how the Union has realised the agenda set out in the Paper. To do so, this study is two-fold: firstly, an ex-post evaluation of the WPG takes place to determine its effectiveness and relevance. Secondly, the data provided in this assessment is used to analyse whether the WPG created the necessary impetus to reform European governance. By evaluating the WPG, and determining whether it followed up on its incentives to reform EU governance, this research seeks closure for the Paper. 
The plethora of academic studies has rarely systematically explored the WPG in its own right (Føllesdal 2003; Höreth 2001; Cygan 2002; Héritier 2001). Such research loses, however, track of the concrete impact of the WPG thereby lacking an understanding of any substantial development in the European governance agenda. This then sets the parameters for the analysis: an ex-post assessment is crucial to determine its incentives in light of the fact that, as stated in the WPG, it "should establish a basis for taking the governance agenda forward" (European Commission [EC] 2001a, 4). Ergo, the WPG's anticipated role in European Governance must not be minimised: it was supposed to bring out the best in the EU. This research is a comprehensive study of the WPG; to conduct a thorough and feasible analysis, it is not possible to cover the whole range of issues concerning all conceivable dimensions of the chosen topic. Above all, the WPG's intention was to involve non-institutional players, mainly civil society, as this was proclaimed to be the solution to the democratic deficit. Hence, although the WPG sets out a range of proposals and improvements, the core revolves around citizens' participation and consequently, the specific provision of 'better involvement' and operational objectives are scrutinised. Similarly, the underlying idea is not to analyse participatory governance at EU level but to consider whether or not the WPG created the necessary conditions for participatory governance to emerge. In a nutshell, the ex-post evaluation methodology is most useful as it provides the necessary criteria and questions. This is an interesting approach and yet not overly used in the existing literature with reference to the Union, its democratic legitimacy and governance.

The article is organized in four parts. The first part lays down the theoretical and methodological framework. In the second part an observation of the rationale behind the establishment of the WPG is conducted. This second part is subdivided into two sections: (a) the background; and (b) the aims and objectives. The third part contains an assessment of the WPG in the light of its central features and the general ex-post evaluation framework discusses two sections: (a) effectiveness; and (b) relevance. The evaluation covers the same scope as the WPG, the findings of which become the basis for a review. Consequently, the fourth part establishes that the WPG provided the necessary impetus to reform governance at the EU level. The argument unfolds in two: the 
EC has realised the agenda set out in the WPG, which has not solely improved EU governance, but at the same time also pushed for further governance reforms, as exhibited in follow-up documents. The WPG has, as promised and hoped, fostered an environment in which participatory governance can emerge and grow. This holds that citizens' participation, in multiple forms but most noticeable the citizens' initiative, has come to the foreground in EU policy- and decision-making. Lastly, the conclusion recaps the most important findings.

\section{THEORETICAL AND METHODOLOGICAL FRAMEWORK}

2.1. Symmetry Principle

The symmetry principle - also known as the all-affected, inclusiveness, congruence and democratic community principle - stipulates that all who are affected by a particular decision should have a right to participate in making it (Dahl 1970). This idea corresponds with this study's argument that the democratic deficit, aggravated by a lack of trust on the citizens' side, was the main rationale in establishing the WPG: "It is particularly acute at the level of the European Union. Many people are losing confidence in a poorly understood and complex system to deliver the policies that they want" (EC 2001a, 3). This research thus aims at thoroughly making explicit the arguments and the cornerstones of the principle as an encompassing theory to scrutinise EU legitimacy and governance.

According to the traditional definition, democracy equals rule by the people but following which criteria is the demos determined? The minimal requirement following the symmetry principle is that those who are affected should have the ability to be political agents. Before delving into the feasibility of this principle, I first offer a few reasons why the congruence principle seems appealing. Firstly, the principle corresponds with classical notions of democracy as found in ancient Roman Law: "quod omnibus tangit, ab omnibus tractari et approbari debet". This translates as "what concerns all, all must discuss and approve". Locke (1689) argued in a similar vein that men are natural equals and hence "no one can be [...] subjected to the political power of another, without his own 
consent" (95). Likewise, for Rousseau (1762) government was only legitimate in so far as it reflected the general will. Admittedly, none of these theories are necessarily 100 per cent matching with the symmetry principle, but the theory nevertheless resonates with these ideals. Secondly, the all-affected principle corresponds with the cosmopolitan theory: the world has grown more closely together and as a result, an occurrence in one part of the world is felt everywhere. This study hence examines and questions the symmetry principle, and particularly whether it is possible for citizens to have a say at a level beyond the nation-state and if this could enhance the democratic character of the Union. As aforementioned, the often-proclaimed solution to the Union's democratic deficit is to include the citizens. For as simple the principle may appear, it generates problems as soon as the demos needs to be identified because it implies an extremely strong notion of democratic political autonomy. This issue only increases beyond the nation-state level as democratic inclusion is increasingly undermined by globalisation: citizens' inclusion does not generally measure up to the participation requirement of the symmetry principle. This is the so-called boundary problem: how to legitimately determine the political community relevant for democracy (Whelan 1983). The first thing to be done is to identify who is affected. Generally, it means that some of the peoples' basic rights or interests have been infringed by political decisions and / or institutions. In a highly decentralised governance system such as the EU where decisions are frequently taken by unanimity at the supranational level, collectively binding decisions intervene massively into the lives of the EU demos. For this reason, the citizenry has to have a voice in the system, and a realistic chance to be heard and to change the course of events. This means that every person in the EU would have the right to intervene in decisions taken by the MS or Union that interferes with his / her rights. Although this is elucidated by the theory, such a situation is clearly infeasible. Moreover, it is not desirable in that it slows down and might even halt the decision-making process. If democracy is so defined as to require that the demos be affected only by such decisions as they have themselves participated in making, then European integration represents a defect in democracy by definition. 
Accordingly, an all-affected principle does not provide any guidance for democratic institutions similar to the EU in particular because of the boundary problem. The WPG nevertheless solved the question of who is supposed to participate in European public policies. Following the Commission, participation is destined for organised civil society. In the WPG, civil society is defined as "trade unions and employers' organisations ('social partners'); nongovernmental organisations; professional associations; charities; grass-roots organisations; organisations that involve citizens in local and municipal life with a particular contribution from churches and religious communities" (EC 2001a, 14). Following this definition, a stakeholder has the possibility to participate, while it may be a single citizen the majority of times it refers to a group of organised citizens. This type of participation is regarded as direct and hence legitimate (Andersen and Burns 1996). It thus seems that the WPG forged a link between EU individuals and the Union; this could fulfil the need for legitimacy and minimise or solve the democratic deficit, which on its turn would enhance the EU's governance structure.

With the above in mind, the ambitious change to maximise participation proposed in the WPG seemed to be derived from the symmetry principle. In this light, participatory governance had been introduced as the solution: it promotes a feasibly kind of democratic legitimacy. Participatory governance is a variant of governance theory that puts greater emphasis on democratic engagement. It seeks to deepen citizens' participation through deliberative practices such as stakeholder and community engagement (Fischer 2012). This principle reflects concerns that at the time of drafting the WPG, representative democracy was no longer adequately supporting the EU's political system and should hence be complemented by direct involvement of civil society.

What matters, in terms of democratic legitimacy, is that citizen's interests are effectively taken into consideration. This seems to be provided by the solution proposed by the WPG and implies a participatory ethos (Bertrand 2014). In sum, the all-affected principle provides a valuable theoretical framework for this research on governance and it can also provide a method of approach as well as provide a fundamental starting point to define the European citizens' participation. One should however keep in mind that although the congruence 
principle serves as the basis to understand the necessity for citizen inclusion, this study does not claim that the EU should adopt the symmetry principle, as the Union would then be faced with a dilemma between efficiency and democracy. Therefore, a question with more implications in the analysis below is whether participatory governance, as based on but not 100 per cent similar to the congruence principle, could emerge at EU level.

\subsection{Ex-Post Evaluation Framework}

The main operationalisation method of this work is a case study; i.e. the examination and interpretation of the WPG to scrutinise citizens' participation and its impact on European governance. In order to do that in a systematic manner, this research opts for an in-depth research design based on the ex-post evaluation framework. Assessments should be carried out after sufficient time has passed to allow for changes to be identified and accordingly this evaluation takes place almost two decades after the adoption of the WPG. It should be stressed that it is not the aim to present and analyse the content of the WPG in an encompassing way but instead to critically trace whether it motivated the EU to undertake governance reforms.

A EU intervention is judged to be successful according to its capability to deal with the situation at hand in an effective and relevant way while remaining coherent with other actions. This normatively informed condition for the quality of an intervention is measured with a list of five indicators that capture the key determinants. Accordingly, the criteria that must be taken into consideration for an empirically manageable assessment that takes place after the intervention has been implemented are the following: effectiveness, efficiency, relevance, coherence and EU added value (EC 2015). To scrutinise all five criteria is beyond the scope of the research, and hence two out of five criteria have been selected: namely, effectiveness and relevance. Participation and effectiveness are chosen because they are presented as the necessary and fundamental conditions of good governance. 
Effectiveness has been chosen due to the fact that it provides information on how successful EU action has been in achieving or progressing towards its objectives. Furthermore, it allows for an opinion on where it falls short and which factors have influenced success and failure. Relevance is significant to look at because it considers the relationship between the needs and problems in society and the objectives of the intervention. This part of the evaluation is significant because in the event that the WPG does not help to address the needs or problems, the question regarding effectiveness is no longer appropriate. Overall, at the hand of these two criteria, it becomes possible to scrutinise whether the WPG was the right tool. There are some matters that this methodology may not help to explain; for example, why some initial actions have (not) been achieved and why participatory governance has (not) emerged.

\section{RATIONALE FOR THE WHITE PAPER}

The creation of the WPG was triggered by various needs and problems of the 1990s and the new millennium. First, European integration had reached a historically important milestone by successfully completing the single market, and the economic and monetary union. The EU had become a political force in its own right and the time had come to re-think and re-organise its policies and operating mechanisms. Second, the eastward enlargements would cause grave institutional challenges: the EU required a new vision for the future as the EU had outgrown its established institutions. Yet, the EU did not solely require a new vision but also the means of putting it into effect, which would be impossible without the involvement of its citizens (Almer and Rotkirch 2004). Third, the EU was experiencing problems regarding its internal affairs: a sense of common purpose was lacking. The EU elite was unsure in regards to what next steps to take and what kind of future to envisage, to the extent that political leadership became questioned (Wincott 2001). This situation was further aggravated around the turn of the millennium as Jacques Santer and his fellow Commissioners resigned following the accusations of fraud (Almer and Rotkirch 
2004). The second and third problems are of importance because they shine light on a bigger issue: the debate on the democratic deficit and a lack of trust.

The lack of trust was mostly exacerbated by the detached relationship between the EU and its citizens. The Union had noticed that "many Europeans feel alienated from the Union's work" (EC 2001a, 7), this citizen's disillusionment became clear by low voter turnout in the European Parliament elections and the significant 'no' vote in the Irish Referendum on the Nice Treaty ratification. The Commission identified four specific issues related to the widening gulf between the Union and its citizens: (a) a perceived inability of the Union to act effectively; (b) the Union rarely gets credit for its actions; (c) Brussels is too easily blamed; and (d) many citizens do not know the differences between the institutions (ibid, 7). Accordingly, the Prodi Commission correctly argued that it was of utmost significance to re-establish the credibility of the EU and to ensure public confidence in the institutions.

President Prodi decided to make better European governance a top strategic priority of his term of office. He wished to improve the effectiveness of the EU by improving the communication and engagement with the wider European public. The EC defines governance as "rules, processes and behaviour that affect the way in which powers are exercised at European level, particularly as regards openness, participation, accountability, effectiveness and coherence" (ibid, 8). Bearing in mind that it would take several years before a new treaty addressing these issues could possibly enter into force, the main vehicle of exploration of these new governance modes was the WPG. In other words, it came to be called 'the Prodi Commission's big idea'.

President Prodi addressed the WPG for the first time in February 2000 in a speech to the EP when he formally identified governance as a strategic priority for his term of office. His speech created high expectations for the WPG due to the fact that he set forward tangible proposals such as broadening public debate, improving the exercise of European responsibilities by the institutions, promoting coherence and strengthening the EU's role in world governance. In particular, Prodi called for civic participation in all stages of the process. This was linked to his idea to create "a new, more democratic form of partnership between the different levels of governance in Europe" (Prodi 2000). Following 
the WPG, the reforms set out in it should be implemented immediately within the existing treaties. The Commission finally adopted the WPG on 25 July 2001. The 35-page document strongly emphasised the five principles of good governance based on the Commission's understanding of governance. With these general principles in mind, the Document offered broadly formulated proposals for change in four areas: (a) better involvement, (b) quality and enforcement of policies, (c) global governance, and (d) examination of policies and institutions. The reforms put forward addressed the EU's democratic deficit. As pointed out by Metcalfe (2001), this WPG is less specific in its proposals than previous white papers but rather represents a broad analysis. The Commission acknowledged that the WPG should not "be seen as a magic cure for everything" but aims to "establish a basis for taking the governance agenda forward" (EC 2001a, 3-4). While some of the promoted ideas were in no respect new inventions, the Document also contained some innovative elements.

\section{GENERAL EX-POST ASSESSMENT}

\subsection{Effectiveness}

The analysis focuses on the specific provision of better involvement because the study's hypothesis is that citizens' participation is perceived to be one of the most successful solutions to the EU's democratic deficit. It is hence important to scrutinise what has been achieved in this respect. The main focus lays on civil society inclusion, as this seems to be the most important one being put forward by the WPG.

Following the launch of the WPG, the Commission organised a public consultation that closed on 31 March 2002. After considering the outcome of the consultation the focus was placed on realising the agenda. The Paper proposed to follow a bottom-up approach by creating a stronger interaction with civil society through establishing a systematic dialogue with CSOs and consultations on EU policy. To do so, it forwarded four specific and necessary changes: (1) the Commission should create an online database comprising details of CSOs; (2) the Committee of the Regions (CoR) and specifically the European Economic 
and Social Committee (EESC) should be more actively involved in the policyshaping process from an early stage on; (3) the EU institutions should seek public and expert views through consultations, the aim is to create a "culture of consultation and dialogue" by adopting "a code of conduct that sets minimum standards" (ibid, 16-17); and (4) the Commission should develop more extensive partnership arrangements in certain sectors.

The importance of the WPG can particularly be seen in the creation of a registry. The EC established a first database in 1997 with the priority to improve its own basis of information. Each DG had a separate database compromising interests groups relevant to the DG's task. This registry changed with the introduction of the WPG, which led to the newly established directory: Consultation, the European Commission and Civil Society (Coneccs), in 2001. This directory was based on the Paper's five principles - openness, participation, accountability, effectiveness and coherence - and urged the Commission to consult civil society more systematically and frequently to increase the visibility of CSOs. To ensure transparency of the policy-making process, the Coneccs database was fully operational from 2002 until 2008 and contained information on various CSOs. Its set up was in such a manner that the general public and CSOs could see which organisations were involved in on-going consultations. The database also gave the Commission the possibility to identify CSOs that could be consulted; it was therefore divided in two sections: one section contained a list of non-profit making organisations organised at EU level, and a second section was a list of the Commission's formal and structured civil society consultation bodies. The aim was to ensure that less frequently consulted parties would gain profile. However, registration was voluntary and did not offer any advantages to the organisations.

In 2008, the Commission set up the Register of Interest Representatives (European Parliament [EP] 2008), a database based on its previous Coneccs Registry albeit different in structure and content. This database was expanded into the Transparency Register in 2011 when the EP joined it (EP 2011). The underlying idea was to increase transparency for the citizens with reference to the EU decision-making process. Following the two institutions, the decisions taken at EU level affect millions of European citizens and to ensure that the 
policies reflect the citizens' real needs, they must be taken openly. The end goal is to guarantee a legitimate decision-making process that is open to proper scrutiny and institutions that can be held accountable. Consequently, the content of Transparency Register elucidates the impression that the EC and EP relied on the symmetry principle - and the WPG - during its establishment. The Register is living proof that the EC and EP are committed to being open about their interactions; this may be linked to the fact that transparency is a key part of encouraging citizens to actively take part in the EU.

Nevertheless, the mechanism has one significant weakness: it is not mandatory. This holds that there are numerous organisations represented at EU level from which no information is available to the public. Therefore, negotiations have recently started on the Commission proposal to make it mandatory. In the Commission's 2010 Communication on Smart Regulation in the EU, it announced to extend the minimum consultation from eight to twelve weeks to further strengthen the voice of the citizens (EC 2012a). Concluding, while the Commission has created an online available database with information that is regularly updated as promised - i.e. the first proposal has been implemented as suggested by the WPG - it has some shortcomings, namely it is not mandatory which decreases the likelihood that every CSO, however small or large, will register. This on its turn makes that the European demos might not be fully represented which, following the all-affected principle, is a significant issue that might undermine the democratic legitimacy of the Union.

Secondly, the role of the EESC and the CoR is to give expert opinion to the decision-making bodies of the EU; while their roles seem to have remained steady over the years, both have in fact increased their importance. On the one hand, the EESC has been stressing its role as representor of organised civil society. On the other hand, the CoR has received the extra function of watchdog: if adopted legislation breaches the subsidiarity principle, it may bring the case before the CJEU. Since their creation, both advisory bodies have been obvious actors to be involved in the decision-making process; hence, it was logical that the WPG set out to establish a more proactive role for these bodies. In several communications that followed from the Paper, the Commission made it clear 
that it wished to increase the role these advisory bodies play in the decisionmaking processes.

In 2001 protocols on cooperation between the Commission and the EESC and CoR were adopted, from now on the bodies can organise consultations on behalf of the Commission. The protocol was concluded to reinforce their function as intermediaries between the Institutions and civil society, and regional and local authorities respectively. In 2002, the EC stressed that the EESC and the CoR are established to assist the Institutions with ensuring representation, "they represent a deep-rooted tradition of consultation" (EC 2002a, 8). In 2005, a new protocol between the Commission and the EESC came into existence to intensify their institutional relations, an addendum followed in 2007 and in 2012 it was officially replaced by a new but similar protocol (European Union [EU] 2005). According to the 2005 protocol "this form of closer cooperation is part of the creation of a more intensive culture of dialogue and consultation with organised civil society and its representatives in the drafting and implementing of the Union's policies and decisions" (ibid, 1). To that end, the EESC has to ensure an ongoing structure dialogue between CSOs and EU Institutions.

The 2012 replacement protocol is similar in structure and content to the 2005 protocol but an updated version was needed with the entry into force of the Lisbon Treaty in 2009 (EU 2012). According to Article 13 of the Treaty on the European Union (TEU), the EESC has become the intermediary between the institutions and the CSOs and plays a privileged role in the implementation of policies. The underlying reason for granting the EESC more powers is to develop participatory democracy to strengthen the Union's democratic legitimacy. In this view, the EESC is of more significance when talking about CSOs than the CoR. The EESC advises the Commission, EP and Council on behalf of civil organisations. The CoR, on the other hand, advises the institutions on behalf of local and regional authorities. Nevertheless, with the Lisbon Treaty in 2009, the role of the official advisory bodies, i.e. CoR and EESC, was confirmed and both may issue an opinion itself, respectively when there is a need to express the interests of economic and societal groups or regional interest. 
Both have increased their powers in the policy-process by signing new arrangements with the EU institutions and by creating a stronger bond between themselves: the bodies are now more actively involved from the beginning on. The Commission put forward that these changes were necessary to better the democratic expression of the Union. All in all, the bodies are however not capable of covering all topics, they do not have to be consulted on all issues, their opinions are not binding and they often deliver their opinions very late in the process. This means that the Institutions may or may not take them into consideration, minimising the agencies effectiveness. While point two has become a reality over the years, much remains to be done to ensure that the EESC and the CoR's opinions are at all times taken into account to ensure that citizens' needs are respected. Although this may be true, the increasing powers for the EESC and the CoR ensure - to a certain extent - a direct link with CSOs, a necessity in order to bring the Union closer to its citizens.

Thirdly, in order to improve the consultation of civil society actors in the shaping of policies, the Commission proposed to introduce general principles and minimum standards for consultation. Before adopting such a document, the Commission consulted the civil society on a draft version of it; the EC encouraged all parties to submit their comments on the proposed general principles and minimum standards, this in itself demonstrates that the Commission wants to create a culture of dialogue and ensure that all are on the same level. To increase transparency, all 88 contributions are accessible via the Internet together with information regarding the objectives and structure of the contributors. This first draft made a distinction between 'open' and 'focused' consultation processes. By the term 'open', the Commission meant the broad public consultation processes where all interested parties and individuals would be able to provide the Commission with input. The term 'focused' referred to situations where the Commission would identify the most appropriate consultation procedures by for example defining the target group(s). Numerous commenters critised the Commission for making this distinction and feared that access to consultations would be limited, minimising the possibility for interested groups to express their opinions. In its final version, the Commission 
therefore no longer used the terms 'open' and 'focused' in spite of the fact that the distinction is still made in content and in practice (EC 2002b).

In 2002 the Commission published a document entitled 'Towards a reinforced culture of consultation and dialogue - General principles and minimum standards for consultation of interested parties by the Commission'. In it, it is explicitly written that the document has been created in order to meet the commitments set out in the WPG, i.e. to reinforce the culture of consultation and dialogue in the EU (EC 2002a). These general principles thus formed the first Commission-wide approach to undertake such consultation. Following the document, consultation is a win-win situation all round. Improving the quality of the policy outcome and at the same time enhancing the representation of civil society is the dual purpose of this document. The Commission - after having taken into consideration the contributions - decided upon the nature and scope of general principles and minimum standards for consultation. The principles are based on the five principles highlighted in the WPG: participation, openness, accountability, effectiveness and coherence. Per analogy, the document sets out five minimum standards: clear content, target groups, publication, time limits, and acknowledgement and feedback. On another note, the minimum standards are also important as it sets out the way for the Commission to decide on target groups in case that it employs the focused consultation process. Most importantly, the Commission should strive for a proper balance between the representatives of different groups, i.e. different interests, and small and large organisations. This brings me back to the CONECCS database, which the Commission uses to make the focused consultations more transparent.

Accordingly, the third point has been respected and a code of conduct, that ensures a culture of consultation and increases accountability, has been created as proposed in the WPG. Albeit the principles and standards set out in the document are not legally binding, the Commission has adopted certain measures to reassure those who fear that a non-legally binding document will have no real effect. The Commission has emphasised on various occasions that the main goal is not to expand the circle of the Brussels insiders. Instead, all views - also minorities - are to be taken into consideration. Most importantly, the process should be transparent: the issues being developed, the mechanisms, 
who is being consulted and why, and what has influenced decisions must be clear. Overall, the content of the conduct corresponds strongly with the 2001 WPG's recommendation and hence the Commission has fulfilled its duty.

A newer code of conduct has been established in Annex 3 of the 2014 Interinstitutional Agreement belonging to the Transparency Register. This code of conduct sets out the rule for all those who register and establishes underlying principles of behaviour in relations with the EU institutions. The code of conduct is however rather linked to lobbying than to CSOs; i.e. it neither creates a culture of consultation nor sets a minimum standard of civil society participation. The rules set out in the document focus on conformity and how parties to the register should behave in their relations with EU institutions and officials (EU 2014). This code of conduct does therefore not embody what was suggested in the WPG.

Fourthly, one notices that in the last years the EU has taken its support for CSOs a step further; not only have civil society interests been given more representation, the quality of the consultations has changed. An initial idea envisaged to include more CSOs was the drawing up of more extensive partnerships agreement than set out in the minimum standards. The aim was to allow the Commission to consult the interested parties more widely than the minimum standards require. Yet, this was dropped in the final version as the EP disagreed with the idea of establishing closer links with CSOs in the form of partnership agreements (Almer and Rotkirch 2004). This does however not hold that closer cooperation with civil society was entirely off the table. In light of the WPG, the Commission has modified and extended its consultation instruments: various policy changes have been implemented to support civil society as an actor in its own right. Important innovations are interactive policy-making (IPM) and the CONECCS database. The IPM initiative was adopted in 2001 to improve governance by collecting and analysing reactions via the Internet. The underlying idea was that enterprises and citizens could have their say on existing and new initatives. At the present time, it is an application to create and conduct surveys and public consultations (EC 2001b). This initiative has resulted in the web portal Your Voice in Europe, a single access point used for all consultations. It offers citizens, consumers, businesses - in a nutshell, all 
interested parties - an opportunity to play an active part in the process of shaping EU policy (EC 2002c). In addition to this, various other online services have been set out by the Commission's departments.

In recent years and particularly in the Union's external relations and development policies have CSOs become visible. In 2012 the Commission published its Communicated entitled 'The roots of democracy and sustainable development: Europe's engagement with civil society in external relations' (EC 2012b). Furthermore, to develop more extensive CSO partnerships, the EU started a joint initiative with its MS to develop EU Country Roadmaps for Engagement with Civil Society. The idea behind these roadmaps is that it ensures a deeper understanding of the civil society landscape and thus an integrated approach among EU actors. The general framework for public consultations can be found in Article 11 of the TEU: "The European Commission shall carry out broad consultations with parties concerned". In a similar vein, Protocol No. 2 on the Application of the Principles of Subsidiarity and Proportionality annexed to the TEU and the Treaty on the Functioning of the EU (TFEU) stipulates that the Commission is obliged to consult widely. All in all, point four also seems to have been respected by the Commission, that is a closer partnership with civil society in certain sectors and overall more participation opportunities for CSOs.

\subsection{Relevance}

As pointed out in the previous parts, the Union was suffering from a legitimacy crisis stemming from popular distrust. This feeling was echoed in the WPG's opening paragraph: "Today, political leaders throughout Europe are facing a real paradox. On the one hand, Europeans want them to find solutions to the major problems confronting our societies. On the other hand, people increasingly distrust institutions and politics or are simply not interested in them" (EC 2001a, 3). The Commission wanted to deliver an adequate response to citizen's ability to relate to the Union and to have a say in the development of rules affecting them, as prescribed by the symmetry principle. 
The WPG presented in 2001 was relevant to EU citizens for two reasons: first, it was the first Commission-wide approach to ensure citizens' participation. Second, the Union has at all times taken pride in itself for addressing the concerns of the peoples of Europe and this was what the WPG set out to do: build a climate of trust between the demos and the Institutions. In this view, the central theme of the WPG was to bring the Union closer to the citizens (Prodi 2001). While the Paper sets out a range of proposals and improvements, the core revolves around the inclusion of CSOs, as the Commission acknowledges the important role civil society plays "in giving voice to the concerns of citizens and delivering services that meet people's needs" (EC 2001a, 14). The WPG accordingly sets out how the European governance agenda can be steered in another direction, i.e. a direction towards more citizens' participation participatory governance. The underlying idea was to breath new life into the European project, to turn ideals into reality, to create a Union for, by and of the people.

Placing citizens at the centre of attention was necessary since the Union is to a certain extent dependent on the powers given by its demos. This holds that a lack of trust goes hand in hand with a less effective and efficient Union. Therefore, the WPG focused on better involvement through opening up the policy process, which was considered the most successful option to ensure a legitimate EU. Furthermore, the WPG was Europe's way of showing that it is not indifferent to its citizens: taking into consideration that various academics claim that the Commission, often perceived as complex and unaccountable by the demos, is the origin of the EU's democratic crisis, the proposals set out in the WPG mainly address the Commission as the responsible institution to increase citizens' participation through more systematic dialogues with civil society. In conclusion, the WPG's relevance to EU citizens should definitely not be underestimated, as it established to respond to the expectations of the EU demos and wants to deliver a Union that can be held accountable (Magnette 2003). 


\section{ANALYSIS}

The four proposed changes laid down in the WPG concerning better involvement of civil society have been respected. A point that has not yet been touched upon concerns the ability of the WPG to reform the European governance agenda. This part provides the linkage between the ex-post evaluation findings and the theoretical framework to briefly consider developments within citizens' participation. These developments are significant to consider because preliminary evidence points out that participation has evolved at EU level. The aim is to then consider whether the WPG provided a fertile environment for participatory governance to emerge, this on its turn discloses if the Paper constituted a stimulus to reform European governance. The EU agenda set out in WPG has been realised through the adoption of several documents envisaging bottom-up involvement in the years following its publication. Accordingly, one of the key tests of the WPG's success is whether and how it has delivered on its claim to reform the governance agenda, in addition to succeeding in terms of citizens' participation through civil society inclusion.

The improvements in citizens' participation are analysed through the consideration of developments in civil society inclusion. A first major step to include civil society shortly after the reveal of the WPG was the Laeken European Council in December 2001. The WPG was to a certain extent the precursor to Laeken: for the first time, it examined and published the problems the EU was facing regarding its legitimacy while at the same time proposing actions. Furthermore, the WPG argued that governance reforms were a requisite part for the European future; hence the Paper provided a push for Laeken. This is also explicitly found in the WPG: "The Commission will also actively participate in the preparation of the forthcoming European council Laeken [...] In doing so, it will draw on the principles of this White Paper" (EC 2001a, 4).

The Laeken Declaration reiterated the concerns expressed in the WPG, i.e. the EU was standing still at a crossroad facing a democratic challenge. As a matter of fact, the Declaration's underlying idea runs parallel with the WPG's action points: bringing the citizens closer through CSOs. Along these lines, Laeken 
suggested that the Union should have a constitution. The overarching aim of this constitution would be to simplify the Union, its institutions and its processes, and simultaneously bring the EU closer to its demos. The Ministers at Laeken decided to create a convention that would be entrusted with the task to prepare proposals for reform; hence the Convention of the Future of Europe was convened. The most important point to take away from this process was the establishment of the Forum. This tool was created in order to ensure a broad debate that would involve CSOs. The organisations that took part in the Forum received regular information on the Convention's proceedings and were asked to provide contributions. Furthermore, civil society could be heard or consulted on specific topics. Participation in the Forum was uncomplicated: sending a written contribution to the Convention was the sole requirement to participate. Ergo, this gave rise to a multiplication of inputs; the forum grew from \pm 200 groups in 2002 to over 500 organisations in 2003. Tellingly, civil society inclusion was assured in the Convention (EU 2001; EC 2001c).

Within the Convention, questions of governance were discussed rather extensively. As drawn attention to in the previous paragraph: the European Convention set the basis for the establishment of a draft constitution for the Union. As aspired by the Laeken Declaration, a final draft Treaty establishing a Constitution for Europe was published in 2003. The Constitution's sentiment was strongly positive and can be summarised with the following words: "Our Constitution [...] favors the many instead of the few; this is why it is called a democracy" (Thucydides 2000, 37). On this point, a first link between participation and democratic legitimacy can be observed: citizens' participation, even to a lesser extent than prescribed by the symmetry principle, still ensures that the EU could be perceived democratic. Relating to this, Title VI of the preliminary draft Treaty was entirely devoted to the democratic life of the EU. Art. 45 focused on the Union's representative democracy while Art. 46 aimed at the principles of participatory democracy. The former sets out that citizens are directly represented at Union level through the EP and that every citizen shall have a right to participate in the democratic life of the Union. The latter states that the Union will maintain an open, transparent and regular dialogue with CSOs, ensuring that citizens have a say (Secretariat of the European Convention 
2003a). A later draft of the Treaty added a fourth paragraph to Art. 46, namely the first mention for including citizen in the policy-making cycle - nowadays the citizen's initiative: "No less than one million citizens coming from a significant number of Member States may invite the Commission to submit any appropriate proposal on matters where citizens consider that a legal act of the Union is required for the purpose of implementing the Constitution" (Secretariat of the European Convention 2003b, 37).

The explicit inclusion of the term 'participatory democracy' in the draft Constitution was the first-ever official mention of this type of democracy at EU level enshrined in an EU Treaty. The Constitution, and in particular Title VI, was denoted by various elements to safeguard citizens' participation: right to information, civil dialogue and so on. As the above evidence highlights, the proposals set forward in the Laeken Declaration and the subsequent Constitution echo the initial actions found in the WPG. An important point to make is that the Convention was never ratified; that is, neither Chapter VI - or any other chapter - nor the citizens' initiative did become reality. Following a period of reflection the Treaty of Lisbon emerged; this Treaty established both the TEU and the TFEU.

The Lisbon Treaty is prima facie entirely similar to the Constitution; yet, in light of the historical experience of the Constitution, some changes had been made to ensure that this Treaty would be ratified. Ultimately, Lisbon was signed in 2007 and entered into force in 2009. Regarding citizens' participation, two elements of the Treaty are significant to consider: the citizen's initiative and participatory governance. Firstly, Lisbon introduced the most concrete and innovate instrument to directly involve citizens: the citizen's initiative which has been operational since 2012. Secondly, as a point of partial contrast with the Constitutional Treaty, Lisbon no longer includes an explicit reference to participatory governance. Art. 10 TEU refers to representative governance, making it similar to Art. 45 of the Constitution, and although Art. 11 TEU is similar - both in wording and in content - to Art. 46 of the Constitution, the referral to participatory democracy has been omitted (EU 2007a; EU 2007b). Before delving into participatory governance specifically, I first evaluate the citizen's initiative as set out in Art. 11(4) TEU: "Not less than one million citizens 
who are nationals of a significant number of Member States may take the initiative of inviting the European Commission, within the framework of its powers, to submit any appropriate proposal on matters where citizens consider that a legal act of the Union is required for the purpose of implementing Treaties".

Comparing the legal basis of the citizen's initiative as laid down in Art. 11(4) TEU and Art. 24 TFEU, it is easy to spot that the wording has remained identical to that of the Constitutional Treaty. The initiative allows citizens to call on the Commission to initiate action. The overarching assumption at the time of its creation was that it was an attempt to make the EU decision-making process more democratic (Krunke and Dalsgaard 2016). This brings me back to the framework employed in this study: participation is a necessary element to perceive the EU as democratically legitimate. On the whole, the citizen's initiative is one of the clearest examples of the introduction of a direct democracy element into EU processes. The background to the citizen's initiative, beginning with Laeken and ending with the Treaty of Lisbon, provides suggestive evidence for the interlinkedness and close connection to the WPG; a fortiori this development stems from the WPG's push for increasing citizens' participation. 60 citizens' initiatives have been submitted, from which 19 were declared inadmissible, 34 have been closed and 7 remain open (European Citizens' Initiative [ECI] 2004). While these numbers may not seem significant at first sight, there are nevertheless meaningful in that they prove that the initiative is in reality used by the demos.

It is important to keep in mind that the WPG did not formulate an explicit policy program to introduce participatory governance but offered a normative template for establishing some model of participatory democracy. I hence claim that even though Art. 11 TEU no longer refers to participatory governance, the Article should nevertheless be read in this light. I make this assumption based on a threefold reasoning: firstly, the wording of Art. 11 TEU has remained exactly the same as Art. 46 of the draft Constitution, which was entitled the principle of participatory democracy. Secondly, the Lisbon Treaty is the Constitution's successor but the wording has been watered down to guarantee that the Treaty would be ratified, so the term 'participatory democracy' was left 
out. Thirdly, the EC has been a leading proponent of the participatory turn (ever since the WPG), which is exhibited by the range of instruments it has introduced for improved consultation and dialogue with CSOs, such as but not limited to ad hoc and online consultations, public hearings, institutionalised consultations in advisory committees and business test panels. Overall, the notion of participatory governance is warmly embraced nowadays by many EU institutions whereas the term is not (Saurugger 2010).

Aside from follow-up treaties, the WPG has pushed the Union to ensure participation in other ways: the Institutions have intensified and extended contracts with societal groups. Whereas civil society was mostly included in the beginning where interests were directly connected and / or affected by the common market, in recent years the Commission has created partnerships in other fields such as social policy and migration (Kohler-Koch and Finke 2007; Smismans 2003). Aside from these partnerships, the Union has put in much effort in online tools. On this point, Your Voice in Europe is one of the most important online policy tools to increase citizens' participation introduced in the follow-up of the WPG. The Union itself describes the web portal as an easier way to engage with the EU as it enables citizens to find information with reference to upcoming legislation, new proposals and there is a possibility for civil society to interact with policy makers online. To date, the Commission advertises all consultation procedures and initiatives across their website. The following are initiatives launched by the Union that have contributed, in one-way or another and some more successful than others, to maximise the possibilities for citizens' participation. A further important step to ensure a more open and transparent communication between the Union and the European demos was the adoption of the EP and Council Regulation regarding public access to documents that came into force in December 2001. Another way through which the Commission has promoted openness is by continuing to develop services such as EUR-Lex (a database containing legal and juridical texts and EU cases), Futurum (an inter-institutional website with information about the debate on the future of the EU) and Governance (a website containing information on the governance reforms). Furthermore, in June 2002 the Commission adopted a Communication on Impact Assessment as part of its so- 
called Better Regulation Package and the procedure has been in place since 2003. It refers to a broad range of stakeholders ensuring that everyone involved will be consulted and will be kept up to date of policies that might affect them. Overall, the Impact Assessment procedure has increased the possibility for the Union to take into consideration the possible impacts on stakeholders, this holds that the Union is more transparent and accountable while at the same time ensuring that everyone's rights are respected and everyone's voices heard.

Ultimately, these examples demonstrate a close link with the symmetry principle. The underlying rationale to enhance citizens' participation is that the EU realised that for it to be considered democratically legitimate, it needed to increase the possibilities for actively participation at EU level. This is similar to the basic assumption of the symmetry principle: democracy is rule by the people. The main problem arising from the all-affected principle was the boundary principle; it appears infeasible to include all European citizens in every decision / policy that affects them. As hinted at in the theoretical framework, the WPG circumvented this boundary problem by designing CSOs as political agents. Consequently, in the early years following the WPG, the Union established stronger links with the EESC, developed more partnership agreements, etc. Overall, civil society inclusion was blooming in the early 2000s because of the symmetry principle underpinning the WPG. In addition, I argue that nowadays more policy tools have been created that no longer solely focus on CSOs but, as prescribed by the congruence principle, also on individuals; the most prominent example being the citizens' initiative but also the many online services such as Your Voice in Europe.

To resume, the WPG was a landmark document in the evolution of civil society participation in EU decision- and policy-making. Though the above discussed initiatives each have their shortcomings and do not necessarily ensure that all citizens' interests are heard, on average citizens' participation has increased; the tools have allowed for more people to speak up. Admittedly, it is unlikely that participatory governance will provide all interest groups with equal chances of making their voice heard since political power is always, to some extent, unequally distributed. I hence conclude that participation is indeed seen as a key to better democratic governance and that the Union has wisely taken this into 
consideration when developing new policies. In conclusion, the WPG was a first important ingredient in the development towards participatory governance at EU level. Its significance is especially noticeable in the Laeken Declaration, the creation of the Convention and the Constitutional Treaty, and lastly in the Treaty of Lisbon.

\section{CONCLUSIONS}

The present article was designed to determine the effects of the Commission's agenda for European governance reforms set out in the WPG, by placing a particular focus on how possibilities for civil society inclusion have evolved since 2001. The most obvious finding to emerge from this study is that governance reforms at EU level have taken concrete shape since the launch of the WPG in 2001. These reforms were necessary to make the decision-making process more democratic, legitimate, transparent and effective because, as highlighted, the Union was suffering from a severe lack of trust and hence was perceived to be in a democratic deficit. Participatory governance was thus considered as the Holy Grail to solve the EU's deficit at the time of drafting of the WPG. It is necessary to mention that the Union should not solely be based on participatory democracy. As a matter of fact, representative democracy does not compete with participatory democracy, but rather complements it.

In a nutshell, the Union aimed to solve or at least minimise its democratic deficit by establishing the WPG in which the focus was put on civil society as the representation of the EU demos. This research draws together the major insights to be gleaned from the symmetry principle and concluded that participatory democracy fully based on the symmetry principle might be regarded as impractical and undesirable at EU level. Taking the above into account leads to ambivalence: an active demos, that is participatory governance, is required to enhance the Union's legitimacy but participation at EU level seems rather problematic following the symmetry principle. The combination is however not impossible as proven by the suggestion made in the WPG: organised civil society. The Paper proposed to ensure more opportunities for CSOs to take part 
in the EU policy process. This brings me to the question posed in the theoretical framework: whether participatory governance - partially - based on the symmetry principle could emerge and be beneficial at EU level? My answer is then yes; the WPG provided for participatory governance along the lines of the all-affected principle.

The analytical findings based on the symmetry principle constituted the basis for the assessment on how the White Paper has scored on the two defined evaluation criteria of effectiveness and relevance. Effectiveness has highlighted civil society inclusion by narrowing down four action plans set out in the WPG and relevance considered the significance of the Paper for EU citizens. Regarding effectiveness, the Commission has realised all it initially set out to do regarding civil society inclusion. In spite of the fact that some ideas have not taken the imagined form or delivered the expected result, it is important that they have been realised. The second part of the ex-post evaluation focused on relevance, also here I did find a positive result: the WPG was strongly relevant to the EU demos due to the fact that it was created as a response to the citizens' cry for a better Union and thus proposed to address weak element within the EU to ensure a Union more responsive, accountable and relevant to its population. Taken together, these findings suggest that the WPG is effective and relevant. This in turn allowed me to establish the causality and the attribution of effects to the intervention.

The analysis revealed how the Union adopted a number of follow-up documents and treaties that have essentially given effect to the initial recommendations and proposals forwarded in the WPG. Through scrutinising these initiatives, I have found a causal relationship between the WPG and a reformed governance agenda at EU level, and even a rather strong correlation with the symmetry principle. In the early years following the WPG, the Union mainly put in on CSOs as proposed in the WPG. In more recent years, however, I notice a shift towards active participation by individuals. At the present time, the citizens' initiative is one of the most explicit expressions of participatory governance at EU level. The beginnings of this process can be found in the WPG. 
In a nutshell, it becomes clear that a shift towards the participatory side has occurred. These findings have significant implications for the understanding of how the WPG provided the necessary push for participatory governance to be discussed and eventually to be materialised. While the WPG was no "magic cure for everything" (EC 2001a, 3-4), the EC has realised its "vision of a brave new world" (Everson 2001). The study certainly adds to our understanding of how the EU tries to develop in favour of its citizens.

\section{REFERENCES}

- Adam, Cygan. 2002. "The White Paper on European Governance - Have Glasnost and Perestroika Finally Arrived to the European Union?" The Modern Law Review Limited no. 229-239. https://www.jstor.org/stable/1097638.

- Andres, Føllesdal. 2003. "The Political Theory of the White Paper on Governance: Hidden and Fascinating." European Public Law, no. 1: 73-86. https:// papers.ssrn.com/sol3/papers.cfm?abstract_id=1752190.

- Beate, Kohler-Koch, and Barbara, Finke. 2007. "The Institutional Shaping of EU-Society Relations: A Contribution to Democracy via Participation?." Journal of Civil Society, no. 3: 205-221. https://doi.org/10.1080/17448680701775630.

- Daniel, Wincott. 2001. "The White Paper, the Commission and the "Future of Europe"." EUSA Review, no. 4 (Fall): 1-8. http://aei.pitt.edu/74/1/GovernanceForum.html.

- Emanual, Bertrand. 2014. "The Discursive Regime of European Participative Governance and the Neoliberal Ideology." Paper presented at Midwest Political Science Association's $72^{\text {nd }}$ Annual Conference, Chigaco, April 2014. https:// halshs.archives-ouvertes.fr/halshs-01048571/document.

- European Citizens' Initiative [ECI]. 2004. Home. http://www.citizensinitiative.eu. 
- European Commission [EC]. 2001a. European Governance: A White Paper. COM (2001) 428 Final. Brussels: the European Union. http://europa.eu.int/comm/governance/white_paper/index_en.htm.

- European Commission [EC]. 2001b. Communication from the Commission on Interactive Policy Making. C (2001) 1014. Brussels: the European Union. http://ec.europa.eu/idabc/en/document/7397.html.

- European Commission [EC]. 2001c. Communication from the Commission on the Future of the European Union. European Governance: Renewing the Community Method. COM (2001) 727 Final. Brussels: the European Union. https://eur-

lex.europa.eu/LexUriServ/LexUriServ.do?uri=COM:2001:0727:FIN:EN:PD F.

- European Commission [EC]. 2002a. Communication from the Commission Towards a Reinforced Culture of Consultation and Dialogue. General Principles and Minimum Standards for Consultation of Interested Parties by the Commission. COM (2002) 0704 Final. Brussels: the European Union. https://eur-lex.europa.eu/legal-content/EN/TXT/?uri=celex:52002DC070.

- European Commission [EC]. 2002b. Communication from the Commission. Consultation Document: Towards a Reinforced Culture of Consultation and Dialogue - Proposal for General Principles and Minimum Standards for Consultation of Interested Parties by the Commission. COM (2002) 277 Final. Brussels: the European Union. http://www.europarl.europa.eu/meetdocs/committees/empl/20021126/ 277277EN.pdf.

- European Commission [EC]. 2002c. Report from the Commission on European Governance. COM (2002) 705 Final. Brussels: the European Union. http://www.europarl.europa.eu/meetdocs/committees/afco/20031106/c om(2002)0705en.pdf.

- European Commission [EC]. 2012a. Communication from the commission to the European parliament, the council, the European economic and social committee and the committee of the regions. Amendment of the financial statement accompanying Regulation (EC) No 297/95. COM (2012) 543 Final. Brussels: the European Union. 
http://ec.europa.eu/transparency/regdoc/rep/1/2012/EN/1-2012-543EN-F1-1.Pdf.

- European Commission [EC]. 2012b. Communication from the commission to the European parliament, the council, the European economic and social committee and the committee of the regions. The roots of democracy and sustainable development: Europe's engagement with civil society in external relations. COM (2012) 492 Final. Brussels: the European Union. https://eurlex.europa.eu/LexUriServ/LexUriServ.do?uri=COM:2012:0492:FIN:EN:PD F.

- European Commission [EC]. 2015. Better regulation: guidelines and toolbox. Brussels: the European Union. https://ec.europa.eu/info/betterregulation-guidelines-and-toolbox_en.

- European Parliament [EP]. 2008. Framework for the activities of lobbyists in the EU institutions. European Parliament resolution of 8 May 2008 on the development of the framework for the activities of interest representatives (lobbyists) in the European institutions (2007/2115(INI)). OJ C 271E. Brussels: the European Union. https://eur-lex.europa.eu/legalcontent/EN/TXT/?uri=CELEX:52008IP0197.

- European Parliament [EP]. 2011. Interinstitutional agreement on a common Transparency Register between the Parliament and the Commission European Parliament decision of 11 May 2011 on conclusion of an interinstitutional agreement between the European Parliament and the Commission on a common Transparency Register (2010/2291(ACI)) ANNEX. OJ C 377. Brussels: the European Union. https://eur-lex.europa.eu/legalcontent/EN/ALL/?uri=uriserv:OJ.CE.2012.377.01.0176.01.ENG.

- Frank, Fischer. 2012. "Participatory Governance: From Theory to Practice." In The Oxford Handbook of Governance, edited by David, Levi-Faur, 457-472. Oxford: Oxford University Press.

- Frederick, G., Whelan. 1983. "Democratic Theory and the Boundary Problem." In Liberal Democracy, edited by James, Roland, Pennock and John, W., Chapman, 13-47. New York: New York University Press.

- Helle, Krunke, and Jens, Christian, Dalsgaard. 2016. "Towards Increased Citizen Participation in Europe: Impact of Current Developments on 
Political Decision Making and Democracy." International Journal of Open Governments, no. 2: 107-130. http://ojs.imodev.org/index.php/RIGO/article/view/58/0.

- Jean-Jacques, Rousseau. 1762. On the Social Contract. France.

- John, Locke. 1689. Second Treatise of Government. London: Awnsham Churchill.

- Les, Metcalfe. 2001. "More Green than Blue: Positioning the Governance White Paper." EUSA Review, no. 4 (Fall): 1-8. http://aei.pitt.edu/74/1/GovernanceForum.html.

- Marcus, Höreth. 2001. "The European Commission's White Paper on Governance: A 'Tool-Kit' for closing the Legitimacy Gap of EU policymaking." Paper presented at Preparing Europe's Future, Brussels, November 2001. Bonn: Centre for European Integration Studies. https://www.zei.unibonn.de/dateien/discussion-paper/dp_c94_hoereth.pdf .

- Michelle, Everson. 2001. "European Agencies: From Institutional Efficiency to "Good" Governance." EUSA Review, no. 4 (Fall): 1-8. http://aei.pitt.edu/74/1/GovernanceForum.html.

- Paul, Magnette. 2003. "European Governance and Civic Participation: Beyond Elitist Citizenship?." Political Studies, no. 1: 144-161. https://doi.org/10.1111/1467-9248.00417.

- Robert, A., Dahl. 1970. After the Revolution? Authority in a Good Society. New Haven: Yale University Press.

- Romano, Prodi. 2000. "2000-2005: Shaping the New Europe." Speech given to the European Parliament, Strasbourg, 15 February 2000. Brussels / Strasbourg: European Parliament. http://europa.eu/rapid/pressrelease_SPEECH-00-41_en.htm.

- Romano, Prodi. 2001. "Speech concerning the White Paper." Speech given to the European Commission, Brussels, 20 September 2001. Brussels: European

Commission. https://www.cvce.eu/content/publication/2002/5/27/e4fbd168-bdd749c9-845e-3826a2bf6b08/publishable_en.pdf.

- Sabine, Saurugger. 2010. "The Social Construction of the Participatory Turn: the Emergence of a Norm in the European Union." European Journal of 
Political Research, no. 4: 471-495. https:/ / onlinelibrary.wiley.com/doi/abs/10.1111/j.1475-6765.2009.01905.x

- Stijn, Smismans. 2003. "European Civil Society: shaped by discourses and institutional interest." European Law Journal, no. 4: 473-495. https://doi.org/10.1111/1468-0386.00187.

- Svein, S., Andersen, and Tom, R., Burns. 1996. “The European Union and the Erosion of Parliamentary Democracy: A Study of Post-Parliamentary Governance." In The European Union: How Democratic Is It ?, edited by Svein, S., Andersen, and Kjell, A., Eliassen, 227-252. London: Sage.

- The European Union [EU]. 2001. Laeken Declaration on the Future of the European Union. SN 300/01/01. Brussels: the European Union. https://www.cvce.eu/en/obj/laeken_declaration_on_the_future_of_the_e uropean_union_15_december_2001-en-a76801d5-4bf0-4483-9000e6df94b07a55.html.

- The European Union [EU]. 2005. Protocol of Cooperation between the European Commission and the European Economic and Social Committee. CESE 1391/2005. Brussels: the European https://www.eesc.europa.eu/sites/default/files/resources/docs/ces13912005_d_en.pdf.

- The European Union [EU]. 2007a. Treaty of Lisbon: Amending the Treaty on European Union and the Treaty Establishing the European Community. 2007/C 306/01. Brussels: the European Union. https://eur-lex.europa.eu/legalcontent/EN/TXT/?uri=CELEX\%3A12007L\%2FTXT.

- The European Union [EU]. 2007b. Consolidated Versions of the Treaty on European Union and the Treaty on the Functioning of the European Union. 2012/C 326/01. Brussels: the European Union. https://eurlex.europa.eu/legal-content/en/TXT/?uri=CELEX\%3A12012M\%2FTXT.

- The European Union [EU]. 2012. Protocole sur la Cooperation entre La Commission Europeenne et le Comite Economique et Social Europeen. DI CESE 5/2012. Brussels: the European https: / / www.google.com/ url?sa=t\&rct=j\&q=\&esrc $=$ s\&source $=$ web\&cd $=8$ \&ved=2ahUKEwjukd3V19rdAhWoBsAKHVikB2AQFjAHegQIBxAC\&url= https $\% 3 \mathrm{~A} \% 2 \mathrm{~F} \% 2 \mathrm{Fwww}$.eesc.europa.eu $\% 2$ Fsites $\% 2$ Fdefault $\% 2$ Ffiles $\% 2$ Fres 
ources\%2Fdocs\%2Fdi_ces5-2012_di_fr.doc\&usg=AOvVaw3k2jwDs5j36OivFQnu18R.

- The European Union [EU]. 2014. Agreement between the European Parliament and the European Commission on the transparency register for organisations and self-employed individuals engaged in EU policy-making and policy implementation. OJ L 277. Brussels: the European Union. https://eurlex.europa.eu/legalcontent/en/TXT/?uri=uriserv:OJ.L_.2014.277.01.0011.01.ENG.

- The Secretariat of the European Convention. 2003a. Draft Constitution, Volume I. Revised text of Part One. CONV 724/03. Brussels: the European Union.

http:/ / ec.europa.eu/dorie/fileDownload.do;jsessionid=yhCklwlyjzp7sI7LcEDB6hYMvtTQy_LWrP6aSg5epFYD_yyKYQ8!2052287358?docId=25 $7387 \&$ cardId $=257387$.

- The Secretariat of the European Convention. 2003b. Draft Treaty Establishing a Constitution for Europe. CONV 820/03. Brussels: the European Union. http://europeanconvention.europa.eu/pdf/reg/en/03/cv00/cv00820.en03.pdf.

- Thucydides. 2000. History of the Peloponnesian War. London: Penguin Classics.

- Wulf, Josefin, Almer, and Matilda, Rotkirch. 2004. “European Governance: An Overview of the Commissions Agenda for Reform." Swedish Institute for European Policy Studies: 9-106. http:/ / www.sieps.se/en/publications/2004/european-governance-anoverview-of-the-commissions-agenda-for-reform-20041u/. 